https://doi.org/10.48009/2_iis_2010_22-29

\title{
USING SOCIAL NETWORKING TO TEACH WHILE ON THE GO YES! THERE IS AN APP FOR THAT
}

Joseph Rene Corbeil, The University of Texas at Brownsville, rcorbeil@utb.edu

Maria Elena Corbeil, The University of Texas at Brownsville, mariaelena.corbeil@utb.edu

\begin{abstract}
The last decade has seen an explosion of social networking services that have been widely adopted by millions of users all over the world. Although the trend to be in close communication with others through Twitter, MySpace, Facebook and other social networking services has permeated higher education, not all faculty are ready to embrace the tools and practices of social networking. This article will present: (1) research on the use of social networking tools in e-learning environments; (2) a review of several popular social networking apps for mobile devices with educational applications; and (3) a description of how one instructor incorporates social networking tools in his graduate educational technology courses.
\end{abstract}

Keywords: Social networking, E-learning, Mobile learning, Educational technology, Online learning, Social presence

\section{INTRODUCTION}

A day in the life of an active professor...

Its Sunday evening and I am getting ready to leave for a 4-day technology conference. Before I go, I want to post a class announcement to each of my online courses. Since the Announcement pages on my Blackboard courses have been replaced with blogs, I can submit a post using my iPhone without having to login to the course. I access the Announcements blog at 8:55 PM, write my message, and set the publication day and time for tomorrow morning.

Monday, 7:05 a.m.- I am on my way to the airport. I check my email to see if there are any messages from students. Two students inform me that they would like some early feedback on a project that is due next week. I reply that I am on the road, but that I will review their projects within the next 48 hours.

7:45 a.m.- I am sitting at the airport waiting to board my flight. I remember to send a quick text message to students, reminding them that I will be out of town for the next 4 days, but that I will be monitoring my email and logging in to the course on my laptop every evening. The message is posted to my class Edmodo account that is automatically routed to students' email, Twitter, or SMS accounts. There! Now, students are aware of my schedule.

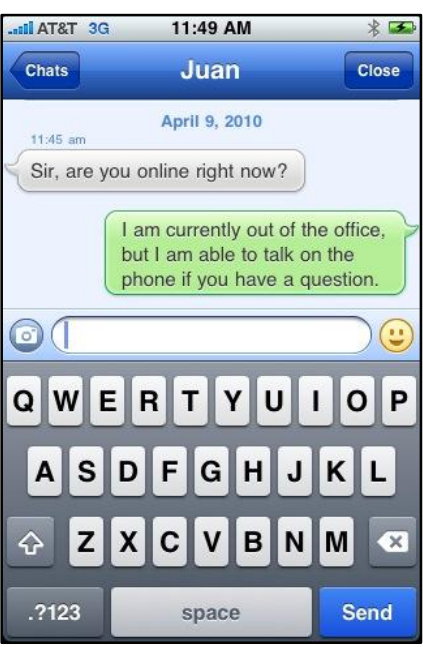

Figure 1. Screenshot of Meebo app on iPhone.
7:55 a.m.- I check my digital Dropbox to see if the final draft of the multimedia presentation has been uploaded by my co-presenter. It has, so I open it on my iPhone using the Documents To Go app. Good, its ready to go. I will review it on my laptop once I am airborne.

\section{3:20 p.m.- I have arrived at my destination and I am} waiting for the shuttle to take me to the hotel. I receive a notification that one of my students has accessed the live chat applet on the course home page. I click on the Meebo app and read the message. "Sir, are you online right now?" I quickly reply that I am currently out of the office, but I am available to talk on the phone if he has a question. "I'm sorry," he replies, "No emergency. I'll email you my question later."

5:00 p.m.- I go to the conference opening reception. While I'm there, I take several pictures of colleagues and students who are also attending the conference. I quickly upload the photos to the Ed Tech Fan page on Facebook and Twitter to share with students and 
colleagues back home.

7:35 p.m.- I am in the hotel room. With the TV on, I power up my laptop to check my email. I quickly provide feedback to the students who requested it and answered the technical question of the student who chatted with me earlier. I go to the class discussion forum, which is also facilitated by a blog, and read through students' comments to this week's discussion question. I respond to a few posts that I found particularly interesting.

8:15 p.m.- I change my online status from 'Available' to 'Away' on my Meebo account and log off of my computer.

\section{Background}

Whether you are on the go or in your office, students are more mobile now than ever. Even campus-based students have less time to meet an instructor during office hours and can benefit from the flexibility and just-in-time learning opportunities afforded by the social networking tools made available by the Web 2.0. Kamel Boulos and Wheelert [5] noted, "the second incarnation of the Web (Web 2.0) has been called the 'social Web', because, in contrast to Web 1.0, its content can be more easily generated and published by users." It is no surprise then that social networking tools and services, such as wikis, blogs, microblogs, and podcasts, exploded in recent years with the emergence of Web 2.0. In higher education, these advancements are being capitalized on for administration, academics, and student support [1]. "On the back of the exponential growth of Web 1.0, Web 2.0 software has emerged to facilitate new online activities, many of which could not have been previously achieved" [5]. These activities are especially advantageous for building dynamic and participatory e-learning environments that can help reduce the distance between the learners, content, and instructor.

One of the challenges for designers and instructors of e-learning environments frequently addressed in the research [5, 8, 13, 14] is how to reduce learner frustration and dissatisfaction derived from feelings of perceived distance from the instructor and fellow students. Baker [2] noted that this distance had to do less with geographical separation than with the quality of the design of the online learning environment and activities. Wang [13] observed that through the exclusive use of traditional asynchronous online teaching methods,

learners have fewer opportunities to participate in more meaningful and relevant ways with the content and each other. He added, “....asynchronous communication is slow and limits the type and amount of communication between instructor and student. Furthermore this type of communication tends to remove any feelings of connection between the student and instructor" [13]. According to Wegerif [14] all learners enter the online learning environment as "outsiders" due to their unfamiliarity with the surroundings (the technology, each other, course content, etc.). He noted that as activities and interactions facilitate the building of an online community, learners have the opportunity to become insiders. Wegerif [14] explains, "it is the line between feeling part of a community and feeling that one is outside that community looking in." Kamel Boulos and Wheelert [5] added that the challenges faced by the students who remain outside, may negatively impact their online experience, motivation, and consequently, learning.

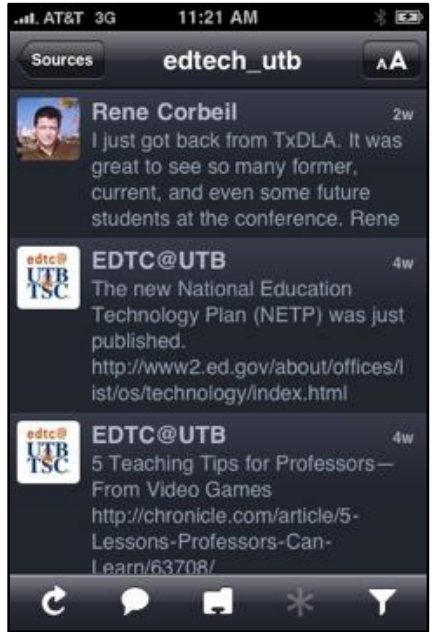

Figure 2. Screenshot of Twitterific on iPhone. $\begin{array}{lr}\text { While in } & 2001, \\ \text { Wang } & \text { [13] } \\ \text { advocated } & \text { for }\end{array}$ synchronous communication in online courses to resolve these challenges, the social networking tools available today provide for graphically-rich, relevant, and reciprocal communications, so that instead of merely attending class, the class becomes part of the learners' daily lives. For example, through Instant Messaging (IM) and microblogs, such as Twitter, students and the instructor can communicate almost instantaneously, thus reducing the time between interactions and distance between participants. Kamel Boulos and Wheelert [5] agreed that the "Web 2.0 also encourages significantly more interaction between users, a feature that many theorists argue is vital in e-learning." In a study published in January 2010, Baker [2] quoted research that substantiated that "interaction is at the heart of the learning experience and is widely cited as a defining characteristic of successful learning in both traditional and online learning environments..." and 
"it is credited as a catalyst for influencing student motivation, active learning and participation among students, and the achievement of learning outcomes." Consequently, successful e-learning environments, designed with multiple technologies for interaction, support, and collaboration $[6,10])$, have been attributed to contributing to learner persistence [5].

The communication power and ease-of-use of social networking services, coupled with the on-the-go availability of mobile devices, means that today, "mobile learning can take place in any location, at any time, including traditional learning environments such as classrooms as well as in workplaces, at home, community locations and in transit" [9]. In addition, the development of mobile applications (apps) of social networking (and teaching) tools, such as Meebo, Facebook, Twitter, and even learning management systems, such as Blackboard, through smart phones and other mobile devices, means that students can be more connected than ever to their courses and its participants, even when they and their instructors are on the go.

\begin{tabular}{|l|l|}
\hline News Feed & 12:06 PM \\
\hline UTB Education...
\end{tabular}

Figure 3. Screenshot of Facebook app on the iPhone.

In addition, concerns raised regarding students' equitable access to high speed Internet in order to benefit from the emerging technologies in elearning environments, are reduced as recent reports reveal that more people have access to wireless Internet and mobile technologies. " $56 \%$ of adult Americans have accessed the internet by wireless means, such as using a laptop, mobile device, game console, or MP3 player" [4]. In fact, the usage that is rising by a surprising percentage is the number of Americans accessing the Internet on mobile devices. The study revealed, "one-third of Americans (32\%) have used a cell phone or Smartphone to access the Internet for emailing, instant-messaging, or information- seeking." Horrigan [4] added, "this level of mobile internet is up by one-third since December 2007, when $24 \%$ of Americans had ever used the Internet on a mobile device." This exponential growth is not limited to the use of wireless mobile technologies. Another report [7] revealed that "the share of adult internet users who have a profile on an online social network site has more than quadrupled in the past four years -- from $8 \%$ in 2005 to $35 \%$ now <Dec. $2008>$." Fortunately, even students who do not have access to social networking technologies through mobile devices, can experience the benefits of the apps because they can be seamlessly integrated into the course and are available online through any computer or mobile device with Internet access.

While previously, students had to accommodate their lives around school, now, through the use of mobile and social networking technologies, learning can fit easily into their lives. Learners can participate actively in their learning by taking advantage of previously unproductive time, such as the commute home (no, not texting, but listening to a podcast) or chatting online with group members about a project, while waiting at the doctor's office. Similarly, the instructor can also be available to students and establish a presence in the class. Through the purposeful integration of social networking tools in e-learning environments, the design and tools of Web 2.0 can be harnessed to promote increased user collaboration, communication, engagement, and motivation through the creation, control, and distribution of relevant learning content and activities.

The following section lists several popular social networking applications, their features and functions, as well as a description of how one instructor incorporates each of them in his online graduate educational technology courses.

\section{SOCIAL NETWORKING YOUR COURSES}

Not satisfied with the limitations of the current courseware management system, I am continually tweaking and adapting the user interface of my online courses through a variety of freely available, open source, social networking tools in order to enhance usability and create a more user-friendly and easily accessible environment for my students. 
Figure 4. Screenshot of the Announcements Page for a course facilitated through Blackboard. The Announcements Page was replaced with a blog to facilitate greater customization and increased social presence.

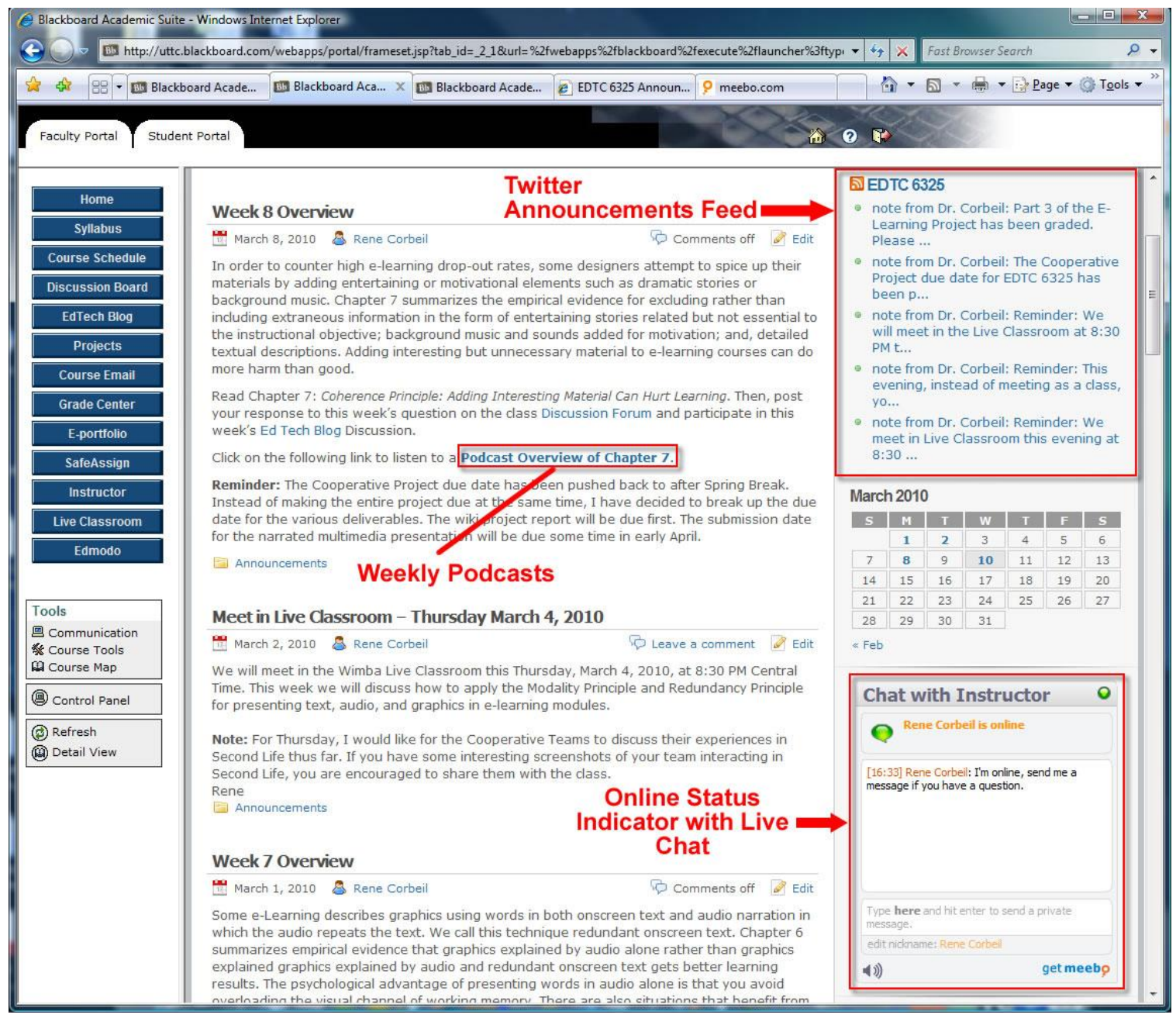

For example, I recently replaced the Blackboard Announcements page with a blog. The new Announcements page is now fully customizable, enabling me to add a host of tools (social networking widgets) to the first page students see when they login to the course.

In addition to the weekly announcements and links to podcasts and class discussion forums, students can also see an RSS feed of the course-related tweets submitted by faculty and students. Edmodo, a social networking tool similar to Twitter but designed specifically for education, is used by all members of the class to send and receive quick status reports from their cell phones and mobile learning devices. This feature enables all members to stay connected without having to login to the course throughout the day.

Also available through the Announcements page is a web-based instant messaging tool with a built-in online status indicator. Through the Meebo widget, students know when I am online and available to answer quick questions. Because this widget is also available as a mobile app, I am able to remain accessible to students even when I am away from the computer. 
Figure 5. Screenshot of the class discussion forum. The class discussion forum was also replaced by a blog, making the class discussions easier to read and follow. Participants can personalize their comments by adding photos to their profiles.

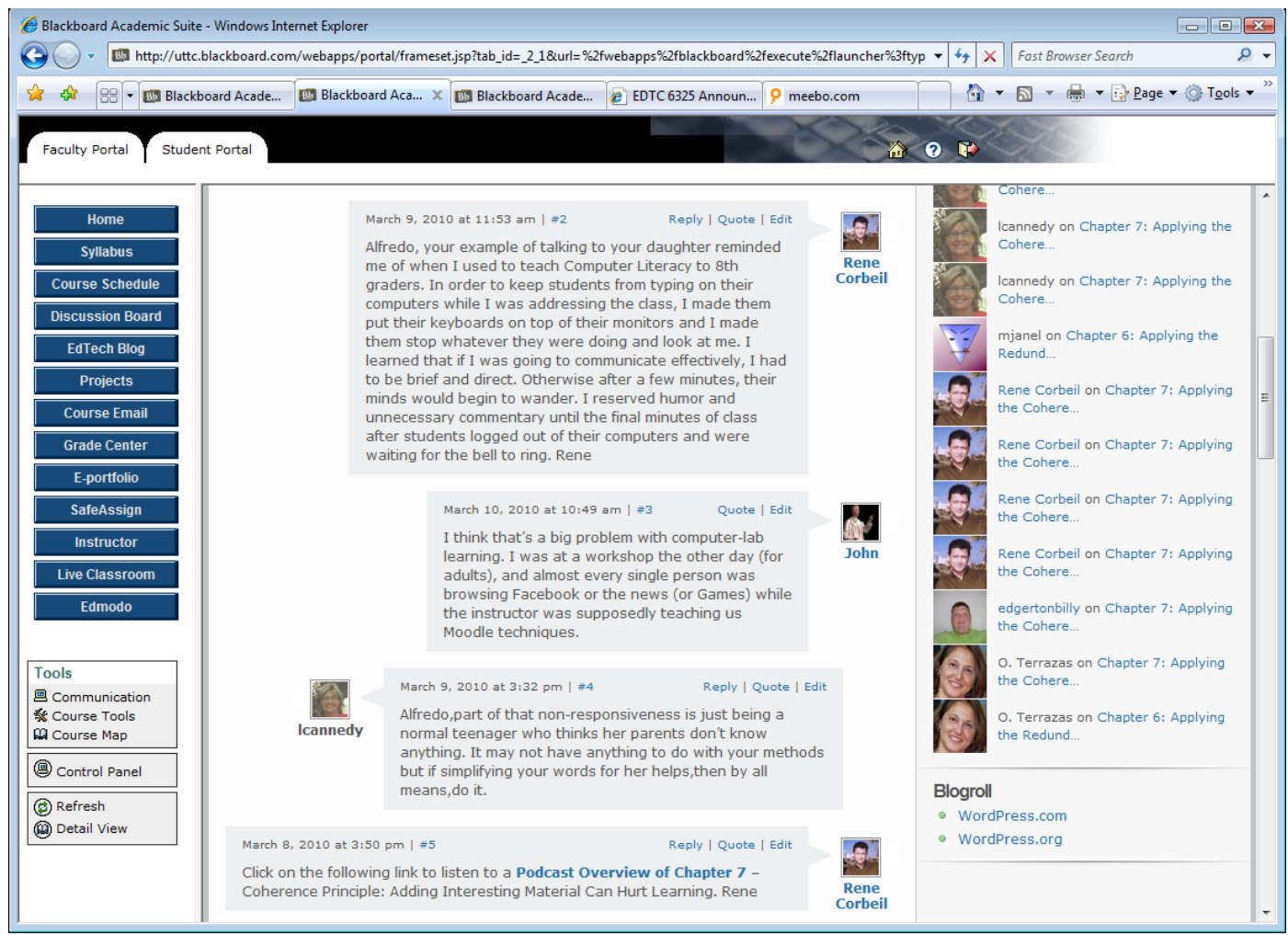

I also replaced the Blackboard discussion forum with a blog to make the class discussions more interactive and easier to follow. While the stagnant coursewaremanaged discussion forums are not customizable and frustratingly non-user friendly, the class blogs, in contrast, are attractive, very customizable, and much more personal. By allowing participants to create a personal profile with a picture, students and the instructor are able to "see" each other every time they post a comment to the blog.

An added benefit of replacing the Announcements and Discussion Forum pages with blogs is that participants can access these resources through their smart phones and web-enabled mobile learning devices without having to login to the course. The microblog and instant messaging tools add an extra layer of connectivity and interactivity to the course that is not possible through the standard courseware management system's communication tools.

\section{The Apps}

Aside from the standard apps available on most smart phones, including the ability to send and receive email and text messages, browse the web, and listen to podcasts, there are a host of social networking web applications and mobile phone apps available for the iPhone, Android, Palm, and Windows Mobile devices for enhancing mobile teaching and learning. The following list includes a variety of apps I use in facilitating my online classes and promoting our programs.

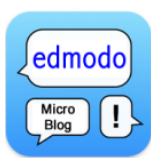

\section{Edmodo.}

www.edmodo.com

A free microblogging platform like Twitter, Edmodo allows educators to set up private online environments for their classes. Features include a microblog, live chat, class calendar, document storage and sharing, and assignment grading, as well as applications for polls, mobile access, public stream (RSS), document viewer, etc. 
[3]. The Web app enables instructors and students to send and receive messages from any Web-enabled cell phone, smart phone, or mobile computing device.

I use Edmodo in my online classes to post quick messages while I am on the move or away from the office. The messages appear on the course Announcements page through an RSS feed. Students also can opt to receive the messages via email, SMS text message, or Twitter. Students in cooperative groups also use Edmodo to stay in constant communication with team members throughout the day, enabling them to discuss team activities without having to $\log$ in to the course.

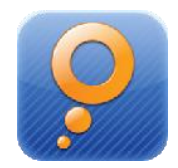

\section{Meebo}

www.meebo.com

A free, instant messaging program, Meebo lets users communicate in real-time across multiple instant messaging platforms (AOL Instant Messenger, Yahoo! Messenger, MSN Chat, etc.). A widget can be added to a Web site to enable visitors to communicate live with the site owner, even if they do not have an instant messaging account.

A Meebo widget was added to the Announcements page of my online courses. The online status indicator lets students know when I am online and available to chat. The Meebo mobile app allows me to be accessible even while I away from my computer. When students have a question, they submit a text message, and if I am able to respond, they usually receive a response within seconds.

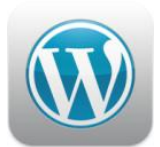

\section{Wordpress \\ wordpress.org}

An open source blog publishing application, Wordpress offers users an easy way to publish on the Web without having to know how to create web pages.

I replaced the Blackboard discussion forum in my online courses with a blog to make the class discussions more interactive and easier to follow. The class blog improves social presence and teacher immediacy by allowing participants to create personal profiles with pictures. This enables the students and instructor to "see" each other every time they post to the blog. The Wordpress mobile app allows me to follow and contribute to the class discussions without having to login to the course.

\section{PBrowser}

pbrowser.mobi

A wiki is a social networking web site that enables individuals and groups to create and update content using a web browser. The archiving feature makes wikis ideal for collaborative work. PBrowser, a client app for PBworks.com, enables users to access their wiki workspaces, search for content, view pages and files, and send links via text and email to others.

Students in my online classes use wikis in their cooperative projects. Working in groups of 4-5, they conduct research on a selected topic and document their work in a wiki. The PBrowser app allows me to monitor students' collaborative efforts on my iPhone or mobile computing device.

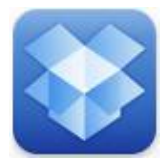

\section{Dropbox \\ www.dropbox.com}

File syncing between online storage and multiple computers is one of Dropbox's main features. Through Dropbox, you can easily share files of any size or type with others by syncing them across multiple computers and mobile devices.

I use my Dropbox to keep important files with me wherever I go. The desktop app and web interface lets me upload work files from my office computer or laptop for easy and convenient retrieval on any computer. The mobile Dropbox app enables me to access my Dropbox while on the go. I like to keep grading rubrics, online resources, and copies of course-related files in my Dropbox for easy access. The Dropbox is also a convenient way to share photos and videos with friends and family.

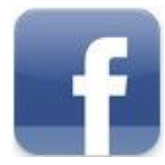

\section{Facebook}

www.facebook.com

Perhaps one of the most popular of the social networking sites, Facebook enables its users to create profiles, post messages, pictures, contact information, and links for friends, colleagues, and others to view. Users can create interest groups and fan pages, and join networks organized by schools, colleges, and organizations. As a social networking tool, Facebook is ideal for promoting programs and organizations.

The Educational Technology program uses Facebook to bring current and former UTB Ed Tech students 
together. We use this forum to post job openings, program and industry-related news, and announcements celebrating former and current students' achievements. The Facebook app makes it easy to read what others are posting, as well as post announcements and pictures while presenting at a conference or on the move.

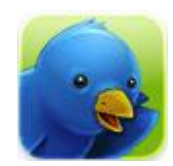

\section{Twitterific}

www.twitterrific.com

Another hugely popular social networking and microblogging service, Twitter, enables its members to send and receive 140character text messages known as "tweets." According to its creators, "Twitter is a real-time information network powered by people all around the world that lets you share and discover what's happening now" [12].

The Educational Technology program uses Twitter to promote the program and its current and former students. The Twitterific app makes it easy to post quick messages and announcements while on the go.

\section{Other Noteworthy Apps}

Although I am not currently using them to facilitate my online classes, the following apps are noteworthy examples of types of tools that could also be applied to mobile teaching and learning.

\section{$\mathrm{Bb}$}

\section{Blackboard Mobile Learn}

www.blackboard.com

For users of the Blackboard Courseware Management System, the Blackboard Mobile Learn app allows students to access course announcements, discussion forums, grades and other resources through a single app. As an information delivery system, this app is convenient. However, since students and faculty cannot currently add or edit the announcements or contribute to the class discussion forums, as an instructional app, its capabilities are limited.

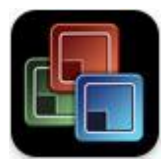

\section{Documents To Go}

www.dataviz.com

This app enables users to view, create, edit, and save Microsoft Word and Excel files, as well as view PowerPoint, PDF, and text files. This is a very handy tool to have when traveling and you need to make some last minute edits before a meeting or conference presentation. It also allows you to rehearse a PowerPoint presentation while on the go.

\section{UP}

\section{Wikipanion}

www.wikipanion.net

Although educators warn students to be wary of the authenticity of information cited in Wikipedia, it remains the most popular reference site on the Internet and a convenient source for the latest information on millions of topics.

The free Wikipanion app makes it easy to search, navigate, and display Wikipedia entries. The fontresizing feature makes it easy to read text on small screens.

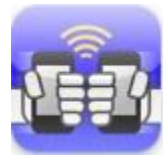

\section{Bump \\ www.wikipanion.net}

This free app comes in handy when you meet colleagues at a conference with whom you want to exchange contact information. Instead of trading business cards, which are easily lost or misplaced, you launch the app and 'bump' your mobile phone with the other person's mobile phone and you immediately exchange contact information. The contact information is automatically stored in your phone's contacts list.

With over 150,000 apps available on the iPhone, and thousands of new apps coming for Android, Palm, and Windows-based smart phones, the possibilities for integrating social networking applications into your traditional and online courses seem endless. The convergence of the exponential growth of the social networking phenomenon, coupled with an increase in the use of smart phones and mobile devices, and an explosion in the availability of Web 2.0 apps, creates unique opportunities for learners and instructors to personalize their learning experiences.

\section{SUMMARY}

These social networking apps are especially advantageous for building dynamic and participatory e-learning environments that: (1) engage learners to be active creators and consumers of learning materials; (2) promote critical reflection strengthened by consistent, reciprocal communication between the learners, the instructor, and the content; and (3) 
provide learner support through built in and just-intime access to classmates and the instructor. Consequently, "trainers, teachers, and learners are beginning to use social networking tools in ways that promise to revolutionize the way e-Learning is produced and consumed. Innovations are carrying eLearning far beyond its initial stages of replicating, then extending, existing classroom-based models" [11].

As the use of Web 2.0 social networking tools increase, further research is necessary to develop best practices, as well as determine their impact on learning outcomes and student satisfaction in elearning environments. The next stage of this study will include expanding the use of social networking tools to other graduate and undergraduate courses in educational technology, as well as study their efficacy in enhancing student satisfaction and learning.

\section{REFERENCES}

1. Armstrong, J., \& Franklin, T. (2008). A review of current and developing international practice in the use of social networking (Web 2.0) in higher education. pp. 1-141.

2. Baker, C. (2010). The impact of instructor immediacy and presence for online student affective learning, cognition, and motivation. The Journal of Educators Online, 7(1), pp. 1-30. Retrieved from http://www.thejeo.com/Archives/Volume7Numb er1/BakerPaper.pdf

3. Edmodo. (2010). Edmodo. Retrieved from www.edmodo.com

4. Horrigan, J. (2009). Wireless Internet Use. Pew Internet \& American Life Project. Retrieved from http://www.pewinternet.org/Reports/2009/12Wireless-Internet-Use.aspx

5. Kamel Boulous, M. N., \& Wheelert, S. (2007). The emerging Web 2.0 social software: An enabling suite of sociable technologies in health and health care education. Health Information \& Libraries Journal, 24(1), pp. 2-23. Retrieved from http://www3.interscience.wiley.com/cgibin/fulltext/118001749/PDFSTART

6. Joyce, K. M., \& Brown, A. (2009). Enhancing social presence in online learning: Mediation strategies applied to social networking tools. Online Journal of Distance Learning Administration, XII(IV), University of West Georgia, Distance Education Center. Retrieved from http://www.westga.edu/ distance/ojdla/win ter124/joyce124.html

7. Lenhart, A. (2009). Adults and social network websites. Pew Internet \& American Life Project. Retrieved from http://www.pewinternet.org/Reports/2009/Adults -and-Social-Network-Websites.aspx

8. McInnerney, J. M., \& Roberts, T. S. (2004). Online learning: Social interaction and the creation of a sense of community. Educational Technology \& Society, 7(3), pp. 73-81. Retrieved from http://www.ifets.info/journals/7_3/8.pdf

9. Mobile Learning Network. (2010). What is mobile learning? Retrieved from http://www.molenet.org.uk/

10. Nagel, L., \& Kotzé, T. G. (2010). Supersizing elearning: What a CoI survey reveals about teaching presence in a large online class. Internet and Higher Education, 13. pp. 45-51.

11. Signorelli, P. (2009). Revolutionizing e-learning: Innovation through social networking tools. Learning Solutions Magazine. Retrieved from http://www.learningsolutionsmag.com/artic les/128/revolutionizing-e-learning-innovationthrough-social-networking-tools

12. Twitter.com. (2010). Twitter. Retrieved from www.twitter.com

13. Wang, A. (2001). Online lectures: Benefits for the virtual classroom. THE Journal. Retrieved from http://thejournal.com/articles/2001/08/01/onlinelectures-benefits-for-the-virtualclassroom.aspx?sc_lang=en

14. Wegerif, R. (1998). The social dimension of asynchronous learning networks. Journal of Asynchronous Learning Networks, 2(1). Retrieved from http://citeseerx.ist.psu.edu/viewdoc/download?d oi=10.1.1.103.7298\&rep=rep1\&type=pdf 